\title{
FACTORS AFFECTING MECHANICAL PROPERTIES OF LOW-DENSITY POLYETHYLENE (LDPE)/STARCH BLENDS: A REVIEW
}

\author{
Ramin Radfar $^{\varpi a, b}$, Hedayat Hosseini ${ }^{\varpi a, c}$, Mehdi Farhoodia ${ }^{a}$, Dominika Średnicka-Tober ${ }^{d}$, Ismail \\ Ghasemi $^{\mathrm{e}}$, Morteza Fathif, Amin Mousavi Khaneghahg \\ ${ }^{a}$ Food Sciences \& Technology Department, National Nutrition \& Food Technology Research Institute, Faculty \\ of Nutrition Sciences \& Food Technology, Shahid Beheshti University of Medical Sciences, Tehran, Iran \\ ${ }^{b}$ Department of Agriculture and Food Policies, Agricultural Planning, Economic and Rural Development \\ Research Institute (APERDRI), Tehran, Iran \\ ${ }^{c}$ Food Safety Research Center, Shahid Beheshti University of Medical Sciences, Tehran, Iran \\ ${ }^{d}$ Department of Functional and Organic Food, Institute of Human Nutrition Sciences, Warsaw University of \\ Life Sciences, Nowoursynowska 159c, 02-776 Warsaw, Poland \\ ${ }^{e}$ Department of Plastics, Iran Polymer and Petrochemical Institute (IPPI), Tehran, Iran \\ ${ }^{f}$ Research Center for Controlled Release, Transfer Phenomena Laboratory (TPL), Department of Food Science, \\ Technology and Engineering, College of Agriculture and Natural Resources, University of Tehran, Islamic \\ Republic of Iran \\ ${ }^{g}$ Department of Food Science, Faculty of Food Engineering, University of Campinas, Campinas- SP, Brazil. \\ rr_date@yahoo.com \\ https://doi.org/10.34302/crpjfst/2020.12.5.1 \\ Article history: \\ Received: \\ 28 August 2020 \\ Accepted: \\ 25 December 2020 \\ Keywords: \\ Low-density polyethylene \\ (LDPE) \\ Mechanical properties \\ Starch

\section{ABSTRACT} \\ Due to the environmental concerns associated with non-biodegradable \\ polymers like low-density polyethylene (LDPE), the production of eco- \\ friendly and partially biodegradable films based on starch/LDPE blends is \\ the point of interest. However, due to immiscibility between hydrophilic \\ starch and hydrophobic LDPE, the mechanical properties of the produced \\ films are not good enough. In this context, several investigations have been \\ conducted to improve the mechanical properties of the films, mainly through \\ the improvements in miscibility and compatibility of two layers. The \\ mechanical characteristics of the films fabricated from these blends are \\ affected by different factors including modification of starch via \\ esterification, cross-linking and thermo-plasticization, starch granule \\ characteristics (amylose to amylopectin ratio, size, and shape) and their \\ content, type, and quantity of compatibilizers, presence of nanoparticles \\ (type and content), using of recycled polymers, type of plasticizers and \\ processing technique. The current article presents an overview of the factors \\ that affect the mechanical properties of LDPE/starch blends.
}

\section{Introduction}

Every year million tons of plastics are produced and discarded after using into the environment (Shimao, 2001). Due to environmental problems of using synthetic polymers, the use of renewable sources to fabricate packaging systems has attracted the attention of the researchers in recent years (Oromiehie \& Rabiee, 2013). Due to unique characteristics of low-density polyethylene (LDPE) such as durability, flexibility, processability, and being lightweight and low price, it is employed in agricultural, pharmaceutical, medical, and food packaging industries. However, nonbiodegradability is one of the disadvantages of LDPE in terms of environmental issues(Torabi Angaji \& Hagheeghatpadjooh, 2004). The addition of biodegradable ingredients can be considered as one of the possible approaches to overcome this challenge (J. C. Huang, Shetty, \& Wang, 1990; 
Obasi \& Igwe, 2014; Swift, 2000; Torabi Angaji \& Hagheeghatpadjooh, 2004).

Starch, as an eco-friendly packaging material, is commonly used to make partially biodegradable plastics. Some properties such as low cost, high availability, renewability, and processability made the starch a promising additive for producing partially biodegradable plastics (Aminabhavi, Balundgi, \& Cassidy, 1990; Gage, 1990; Raghavan $\&$ Emekalam, 2001). In the mid of 1970s, for the first time, native starch was used as a filler into LDPE-based plastic (G. Griffin, 1994; G. J. L. Griffin, 1977; Mali \& Grossmann, 2003). After discarding of packaging containing LDPE/starch into the environment, in the effect of microorganisms' attack to starch, the porosity and surface area/volume ratios are increased, and as a result, the improvement in the rate of oxidation, ultraviolet photodegradation, and biodegradability of the mentioned polymers can be achieved (G. Davis, 2003; Nikazar, Safari, Bonakdarpour, \& Milani, 2005).

The effect of starch on the mechanical properties of LDPE/starch blends has been previously investigated by different authors (Arvanitoyannis, Biliaderis, Ogawa, \& Kawasaki, 1998; W. Liu, Wang, \& Sun, 2003; Lu, Xiao, \& Xu,
2009; Psomiadou, Arvanitoyannis, Biliaderis, Ogawa, \& Kawasaki, 1997; Thakore, Iyer, Desai, Lele, \& Devi, 1999). Nearly all of these researches indicated that the addition of starch has a negative impact on the mechanical properties of these blends. This effect is due to the differences in the nature of the two blended phases (starch and LDPE) (Figure.1). Starch as the dispersed phase, has hydrophilic nature, in contrast, LDPE as the continuous phase, is a hydrophobic polymer (W. Liu et al., 2003; Samper-Madrigal, Fenollar, Dominici, Balart, \& Kenny, 2015). In order to overcome this problem, some attempts have been carried out to improve their compatibility and increasing interfacial adhesion between LDPE and starch (Sabetzadeh, Bagheri, \& Masoomi, 2016). In this regard, enhancing the compatibility between LDPE and starch through different strategies has been investigated in several studies; however, a comprehensive review regarding the application of developed techniques to overcome this problem in packaging systems was not published yet. Thus, in the present paper, for the first time, the factors affecting the mechanical properties of LDPE/starches blends will be discussed.

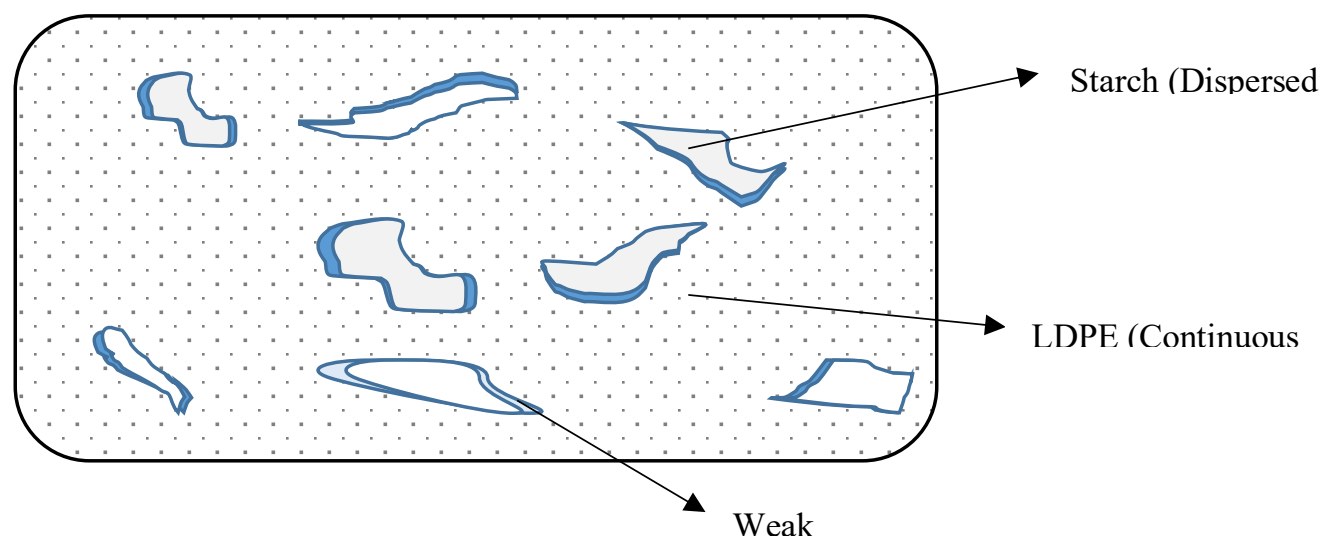

Figure 1. Schematic view of starch dispersion in the LDPE matrix

\section{Effects of starch modification}

Starch in natural forms without any modification could not be used in conventional methods of producing plastics. By the modification process, the heterogeneous structure of native starch granules is converted to a homogeneous structure (Matzinos, Bikiaris, Kokkou, \& Panayiotou, 2001). Some techniques have been 
introduced for modifying the structure of starches. In the following sections, an overview of the most used techniques will be provided.

\subsection{Effect of thermo-plasticization of starch}

The crystalline and semi-crystalline part of starches can be converted to amorphous forms by application of high temperature and pressure in an aqueous environment (Prinos, Bikiaris, Theologidis, \& Panayiotou, 1998). In this condition, due to gelatinization, the native starches swell by absorption of water, and after heating, their crystalline structure is destroyed, and hydrogen interactions between glucose units are broken (Rodriguez-Gonzalez, Ramsay, \& Favis, 2003). Gelatinized starch characteristics could be further improved by the addition of plasticizers. Plasticized and gelatinized starches are known as thermoplastic starch (TPS) (Phetwarotai, Potiyaraj, \& Aht - Ong, 2012).

TPS is a type of gelatinized starch with an amorphous structure that as opposed to dry starch, is capable of flow and thus when blended with synthetic polymers like LDPE, can behave similarly to conventional polymer-polymer mixture (Rodriguez-Gonzalez et al., 2003). By the application of heat and shear stress, TPS can be molded or shaped. This characteristic allows TPS to be processed with common techniques used in plastic manufacturing industries (Bastioli, 1998; Gomez \& Aguilera, 1984; Kokini, Lih-Shiuh, \& Chedid, 1992). The amount of starch in the LDPE/starch film formulation can be increased with thermo-plasticization of starch granules (BeMiller \& Whistler, 2009).

Prinos et al. (1998) showed that LDPE-thermoplasticized corn starch had superior mechanical properties than LDPE/native corn starches. Garg and Jana (2007) showed that the addition of native starch to the LDPE matrix, in comparison with other modified starches, could reduce the mechanical properties of the blends.In another study, one-step processing with a single screw extrusion system was employed to produce LDPE/thermoplastic starch film with unique characteristics (Rodriguez-Gonzalez et al., 2003). The authors indicated that the developed films had high elongation at break (EB), Young's modulus (YM), and tensile strength (TS) in comparison with LDPE/native starch blend. It also was found that despite the absence of any interfacial modifier, the film formulation containing LDPE/TPS with respective ratio of 55:45 retained $94 \%$ of $\mathrm{EB}$ and $76 \%$ YM of LDPE film. Surprisingly, when the film was fabricated by a composition level of 71:29 LDPE/TPS, the film maintained $96 \%$ of EB and $100 \%$ YM of LDPE film.

The utilization of native corn starch in film production is limited due to its low water solubility and brittleness (Eskandarinia, Rafienia, Navid, \& Agheb, 2018). The mechanical performance of thermoplastic corn starch/LDPE at various ratios was evaluated by Oromiehie, Lari, and Rabiee (2013). It was reported that as the starch concentration increased, TS and EB showed a decreasing trend, but YM increased. The decrease of TS is related to the tough nature of LDPE and the brittle structure of starch. The addition of starch to LDPE film formulation leads to matrix embrittlement, due to the replacement of a tough matrix with a brittle polymer (Chiu, Lai, \& Ti, 2009; Da Róz, Carvalho, Gandini, \& Curvelo, 2006). The reduction of $\mathrm{EB}$ with the incorporation of thermoplastic corn starch into LDPE film formulation is also attributed to 1) the weakening of the London forces between LDPE layers and 2) the fact that elongation at break of starch itself is lower than LDPE (Matzinos, Tserki, Gianikouris, Pavlidou, \& Panayiotou, 2002).

The effect of different compatibilizers on mechanical properties of starch/LDPE films was investigated by several scientists and will be discussed in the following sections (Bikiaris et al., 1998; Girija \& Sailaja, 2006; Raquez et al., 2011).

\subsubsection{Effect of type and content of plasticizer}

During the production of biodegradable polymers from starch, due to the presence of strong H-bonds in granules, starches degrade before melting, but by using plasticizers, their melting point decreases (Lorcks, Pommeranz, Klenke, Schmidt, \& Heuer, 2000; Radfar et al., 2019). Plasticizers reduce the strong hydrogenic interactions within the starch polymers and forming 
new bonds between starch and plasticizers (Bikiaris, Prinos, \& Panayiotou, 1997).

In the presence of a plasticizer, the dispersion capability of the starch in the polymeric matrix improves and subsequently interfacial adhesion between phases (Fang, Fowler, Tomkinson, \& Hill, 2002; Garg \& Jana, 2007; Kiatkamjornwong, Thakeow, \& Sonsuk, 2001; Kim \& Lee, 2002; Sabetzadeh, Bagheri, \& Masoomi, 2012; Y. J. Wang, Liu, \& Sun, 2004), flowability at elevated temperatures and ductility of the blends (Cerclé, Sarazin, \& Favis, 2013) develop.

The type and quantity of plasticizers along with processing conditions are three of the most important factors that affect the physical properties of prepared TPS (Kalichevsky \& Blanshard, 1993; Orford, Parker, Ring, \& Smith, 1989; Poutanen \& Forssell, 1996; Shogren, Swanson, \& Thompson, 1992). Glycerol, sorbitol, glycol, urea, ethanolamine, and water are the main plasticizing agents which can be used in preparation of TPS (Fishman, Coffin, Konstance, \& Onwulata, 2000; M. Huang, Yu, \& Ma, 2005; Mazerolles et al., 2019; Shi et al., 2007; Smits et al., 2001).

In the gelatinization process low molecular weight plasticizers such as water and glycerol are the most active ones due to their high affinity to the starch molecules. Moreover, by application of high molecular weight plasticizers (e.g. polyglycerol), the gelatinization temperature of starches increases (Taghizadeh \& Favis, 2013). The reason for this phenomena is not completely clear, but according to Perry and Donald (2002), the most important reason is the reduction in the rate of plasticizer penetration to granules, along with increasing plasticizers molecular weight (Perry \& Donald, 2002).

According to Arvanitoyannis et al. (1998), in prepared blends of LDPE and two types of starch (rice and potato) as fillers, in the presence of different amounts of water ( 5 to $20 \%$ ) by a twinscrew extruder, due to the plasticization effect of water, percentage elongation improved and tensile strength decreased as the water content of blends increased.

The effect of glycerol on the mechanical and physical properties of LDPE and rice starch blends was investigated by Y. J. Wang et al. (2004). The tensile properties of these blends after the addition of glycerol and production of thermoplastic starch improved which is associated with better dispersion of rice starch in the matrix and strong interaction between two phases.

Taghizadeh, Sarazin, and Favis (2013) reviewed the effect of high molecular weight plasticizers from the polyol family, including glycerol, sorbitol, diglycerol, and polyglycerol in TPS/PE composites. They reported that starch could react with poly and di glycerols better than glycerol. This was due to the high number of hydroxyl groups in these compounds which are substituted by etheric bonds. By substitution of these functional groups, the conformational flexibility and molecular movements of chains during mixing improved. Consequently, with increasing molecular flexibility, the interaction between molecules during mixing increased and as a result, in comparison with glycerol, the miscibility of diglycerol and polyglycerol with starches improved. The prepared blend with polyglycerol and without compatibilizer had a higher EB; on the other hand, sorbitol-TPS/PE blend was rigid and had higher YM and TS. This effect is due to recrystallization ability of sorbitol at ambient temperature and forming rigid characteristics.

The effect of plasticizer concentration (glycerol in three concentrations of 25,30 and $35 \%$ ) on the LDPE/corn starch film properties was investigated by Pushpadass, Bhandari, and Hanna (2010). Their finding showed that increasing glycerol content could significantly decrease TS and YM of composites, which can be attributed to the weak intermolecular interactions in the film matrix due to free volume increasing, and separation of starch and LDPE phases along with increasing glycerol content.

\subsection{Effect of starch esterification}

Another approach to incorporate starch in polyethylene and enhance the compatibility between two immiscible polymers is rendering its hydrophobic character by esterification or etherification (Seidenstücker \& Fritz, 1999). In 
these processes, hydroxyl groups of starches are replaced by hydrophobic functional groups (BeMiller \& Whistler, 2009; Mohammadi Nafchi, Moradpour, Saeidi, \& Alias, 2013; Seidenstücker \& Fritz, 1999; Wesslén \& Wesslen, 2002).

Evangelista, Sung, Jane, Gelina, and Nikolov (1991) investigated the mechanical properties of LDPE containing starch octenyl succinate aluminum complexes. Based on their results, the prepared films with octenyl succinate aluminum had better mechanical properties than the films containing native starches.

According to Thiebaud et al. (1997), esterification of starch with fatty acid chloride (octanoate starch with degrees of substitution 1.8 and 2.7) could improve the mechanical properties in comparison to LDPE/native starches blends. The ester groups serve as an internal plasticizer and can improve the EB of the LDPE/starch film. The increasing degree of substitution and length of fatty acid chains also improved the properties of the prepared blend.

In another study, the mechanical performance of acetylated and phthalated tapioca starch/LDPE blends with and without LDPE-co-glycidyl methacrylate copolymer as a compatibilizer was tested by Sailaja (2005). The authors observed that the esterification of starch significantly reinforced the mechanical characteristics of the films. Furthermore, they reported that the incorporation of compatibilizer into film formulation led to further improvement in the mechanical performance of the films. Likewise, Sailaja and Seetharamu (2009) showed that blends containing LDPE and esterified starches (acetate and phthalate) in the presence of LDPE-co-glycidyl methacrylate as compatibilizer demonstrated better mechanical properties than blends containing native starches. Their observation also revealed that starch esterified with phthalate performed better than starch esterified with acetate. However, TS and YM of the blends containing phthalate esterified starch were close to those of pure LDPE.

The processability and thermo-plasticity of starch blends are directly related to the size of ester groups. As mentioned above, ester groups act as internal plasticizers (Sagar \& Merrill, 1995). The esterified starches with different kinds of ester groups have been blended with LDPE. The most frequently used ester groups are carboxy methylate (K. A. Kumar \& Soundararajan, 2016), polyacrylate (Kiatkamjornwong et al., 2001), acetate (Thakore et al., 1999), hydroxypropylate (Swanson, Westhoff, \& Doane, 1988), fatty acid esters (e.g. methyl oleate) (Sagar \& Merrill, 1995; Thiebaud et al., 1997), adipate and acetylate (Nakamura, Cordi, Almeida, Duran, \& Mei, 2005) and tert-butyl acrylate and methacrylamide (M. Raj, Savaliya, Joshi, \& Raj, 2018).

In conclusion, the modification of starch by esterification improved the hydrophobicity and thermo-plasticity of the blends, and mechanical properties of the prepared mixtures were better than those of untreated starch.

\subsection{Effect of starch modification by cross- linking}

As mentioned above, the poor mechanical characteristics of starch-based films have restricted their industrial applications. Cross-linking of starches is another chemical modification process that commonly led to the improvement of mechanical properties of the starch-based films. It should be noted that although cross-linking is a useful strategy to reinforce the mechanical properties of films, the current starch cross-linking techniques are expensive and toxic. The citric acid (CA) is a non-toxic trifunctional additive that is used as a plasticizer, cross-linking and partial esterification agent. It also hydrolyzes starch polymers and produces low molecular weight chains as a side reaction (Olsson et al., 2013). Citric acid could improve fluidity of TPS by deterioration of the chain entanglement and weakening of the interactions in starch molecules (H. Liu, Xie, Yu, Chen, \& Li, 2009).

N. Reddy and Yang (2010) used citric acid as a cross-linker to improve the mechanical properties of starch-based films. The possible crosslink reaction between citric acid and starch is presented in Figure.2. Citric acid cross-linked starch films had 1.5 fold TS when compared with non-crosslinked films. Furthermore, it was found that the 
value of TS in the developed film was higher than those reported for most cross-linked starch and synthetic polymer blended films previously developed. In another research, Ghanbarzadeh, Almasi, and Entezami (2011) cross-linked potato starch to improve the mechanical properties of potato starch/LDPE blend film. The authors showed that following an increase in the citric acid concentration, TS increased and EB decreased. This effect has been attributed to hydrolyzing branched chains of starch molecule in the presence of citric acid that led to the formation of a highly linear structure. It resulted in increasing the number of H-bonds between the starch chains and increasing TS in the produced films.

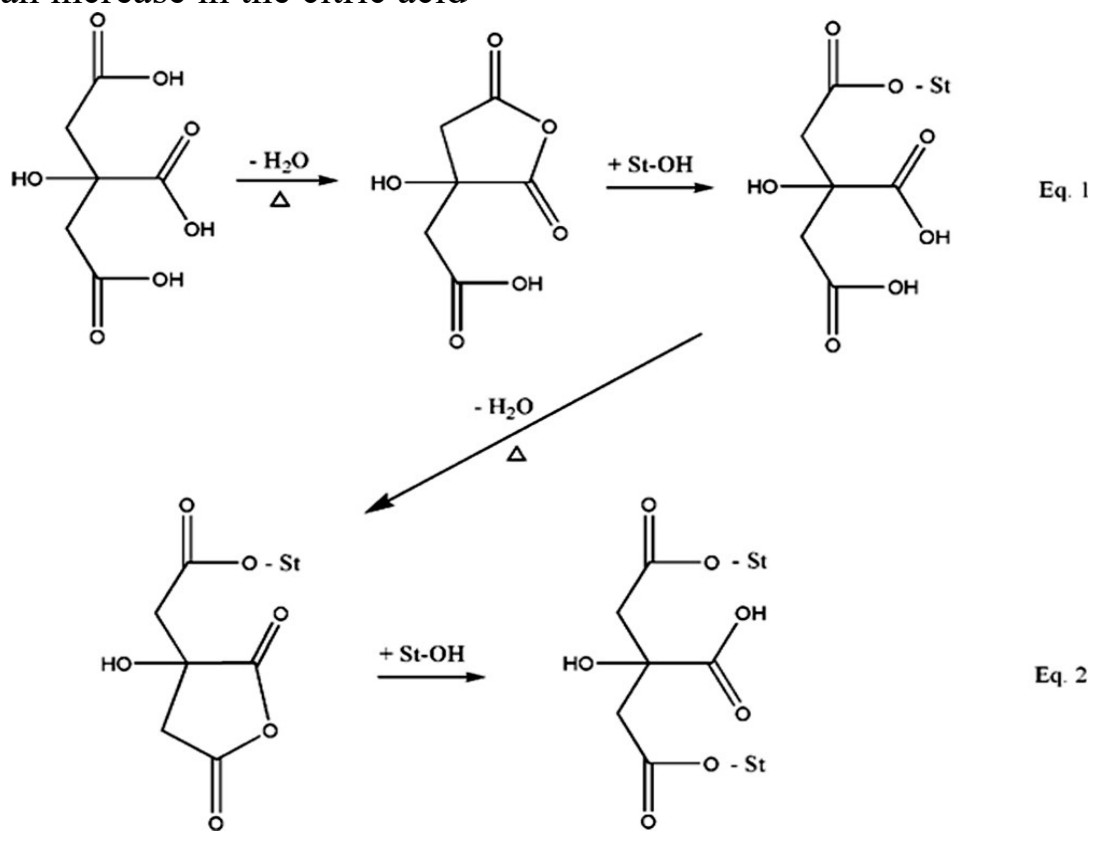

Figure 2. The possible crosslink reaction between citric acid and starch (Kahar et al., 2012).

Kahar, Ismail, and Othman (2012) reported that compatibilization of the PE/natural rubber/tapioca starch systems with citric acid could improve the tensile properties and decrease the surface tension of the blends. They concluded that low molecular weight TPS with better fluidity easily dispersed in the $\mathrm{PE} /$ natural rubber system.

Ning, Jiugao, Xiaofei, and Ying (2007) studied the effect of citric acid on the properties of TPS/LLDPE blends. They used a one-step extrusion method for plasticization and blending of starch and PE. The obtained results showed that a small amount of citric acid (2\%), could greatly enhance the TS and EB of the blends. This may be due to the improvement of interfacial adhesion between two polymers used to fabricate the film. Interestingly, the TS and EB of the developed film incorporated by $2 \%$ citric acid were similar to pure PE. Beyond this concentration, the mechanical performance of the films decreased. This is attributed to the acidolysis of starch in higher citric acid concentration, which led to the complete deterioration of the starch rigid structure. Fouriertransform infrared spectroscopy (FTIR) analysis also showed that in the presence of citric acid, hydrogen bonds between TPS and glycerol as plasticizer strengthened.

Commonly, in order to cross-linking of starch in polysaccharide industry, epichlorohydrin was used (Kuniak \& Marchessault, 1972). In their study, Garg and Jana (2007) used epichlorohydrin as cross linker of corn starch to improve the mechanical properties of corn starch/LDPE film. The mechanical performance of the developed films was evaluated by different mechanical parameters such as TS, EB, melt flow index, and burst strength. It was found that when LDPE was mixed with $7.5 \%$ native starch, there was a reduction in TS, EB and melt flow index but burst strength increased. On the other hand, the values of 
TS, EB and melt flow index of the films incorporated by cross-linked starch were notably greater than those containing native starch. From a morphological point of view, the films produced by cross-linked starch/LDPE were smoother than those obtained from the native starch blend films. The good mechanical properties of the films fabricated by cross-linked starch/LDPE films may be associated with the absence of pores and crakes in their structure. Furthermore, from a chemical perspective, this effect is related to decreasing the hydrophilic nature of native starch after crosslinking. But, in cross-linked starch, the $\mathrm{OH}$ - groups on starch molecules interact with epichlorohydrin and produce mono/di-glycerol ether starch (Hamerstrand, Hofreiter, \& Mehltretter, 1960). The reduction of hydroxyl groups in starch structure decreases the hydrophilic nature of cross-linked starch, and as a result improves the homogeneity and compatibility of the starch/LDPE blend. Likewise, it has been reported that the crosslinking of potato starch with different concentrations of epichlorohydrin $(0.1, \quad 0.5, \quad 1.0$ and $2.0 \mathrm{~g}$ epichlorohydrin per $100 \mathrm{~g}$ of starch) improved TS, EB and strain energy of the films (Kim \& Lee, 2002).

\section{Effect of starch granules characteristics 3.1.Impact of granular structure}

The granule size of starches is another important factor that affects starch/LDPE film properties. The effects of variation in granule size of different types of starch including corn, wheat, rice and potato starch on mechanical properties of starch/LLDPE films were examined by Lim, Jane, Rajagopalan, and Seib (1992). The lowest value of TS was found for the films produced with potato starch (highest granular diameter), while the highest TS was observed in case of rice and small particle corn starch produced by acidic hydrolysis of native corn starch with average granule size of $2 \mu \mathrm{m}$ (the smallest one). Moreover, among unmodified and native tested starches including corn, wheat, rice, and potato starch, the films containing rice starch had the greatest TS. Taken together, there was a negative correlation between granular starch size and mechanical strength of the films. A similar trend was reported for the elastic modulus (EM) and yield strength of the studied films containing different granule sizes. In this regard, the prepared films with small particle corn starch and potato starch had the highest and lowest yield strength and $\mathrm{EB}$, respectively. Due to the uniform dispersion ability of small particle starches in LDPE/starch matrixes, less discontinuity was observed in the produced films. As a result, it can be said that with using small particle corn starch, it is possible to increase the starch content in the film, without any decrease in film quality (Lim et al., 1992).

Willett (1994) studied the mechanical properties of starch/LDPE composites as a function of granule size by using unmodified corn starch and potato starch. The obtained results revealed that TS and tensile modulus of composites were more sensitive to granule diameter, while this factor had no significant effect on EB.

\subsection{Amylose to amylopectin ratio}

According to Mani and Bhattacharya (1998), in addition to granular structure (shape, size), the composition (amylose and amylopectin ratio) of starches could affect the mechanical properties of LDPE/starch blends. They prepared polyethylene blends with four different kinds of corn starches including unmodified waxy corn (involving 100\% amylopectin), industrial corn (with approximately $70 \%$ amylopectin and 30\% amylose), common corn, (containing approximately 50\% amylopectin and $50 \%$ amylose) and an unmodified high amylose starch (consisting of approximately 30\% amylopectin and 70\% amylose). According to their findings, blends including waxy corns were characterized by higher EB and TS in comparison with other ones, which can be correlated with crosslinking between highly branched amylopectin and polymer. Their results also revealed that as amylose content of prepared blends increased up to $50 \%$, TS and EB decreased and then again increased when amylose content reached $70 \%$. Formation of the cocontinuous phase with synthetic polymer had a great role in this regard. 


\section{Effect of starch content}

The increase in the proportion of starch in LDPE/starch blends without any adverse effect on film mechanical properties attracted considerable attention. However, based on the previous investigations, increasing starch content above 30 $\%$ in the formulation, decreased EB and increased TS of the films (Arvanitoyannis et al., 1998; Nawang, Danjaji, Ishiaku, Ismail, \& Ishak, 2001; Psomiadou et al., 1997).

In this context, Sabetzadeh et al. (2012), prepared malleted LDPE/corn starch films containing different concentrations of thermoplastic corn starch (from 5 to $40 \%$ ) and constant LDPE-g-MA (3 wt \%). Within the investigated concentration range, the blends containing $25 \%(\mathrm{w} / \mathrm{w})$ of thermoplastic starch had the best mechanical properties. The authors concluded that the uniformity of particle distribution in the matrix decreases as the concentration of starches increases.

\section{Effect of modification of LDPE by compatibilizers}

As previously mentioned, utilizing a plasticizer could improve dispersion of starch in polyethylene blends. However, the resultant blends due to limited interactions between hydrophobic PE and hydrophilic thermoplastic starch still are
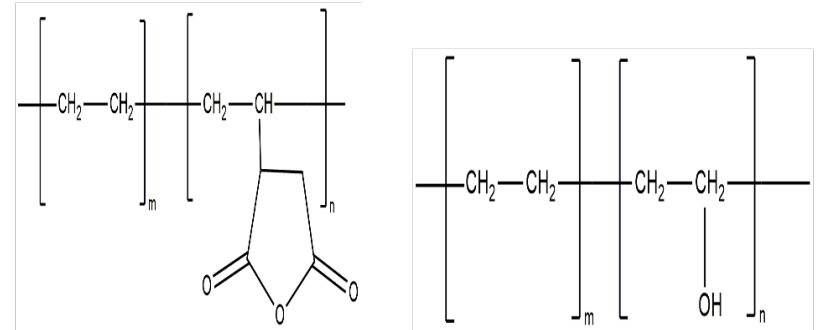

polyethylene-graftedmaleic anhydride
Ethylene-vinyl alcohol $(\mathrm{EVOH})$

immiscible, have poor performance and tend to separate (B. Raj, Annadurai, Somashekar, Raj, \& Siddaramaiah, 2001). The effective way for increasing compatibility between thermoplastic starch and polymer and also decreasing interfacial properties is the addition of a compatibilizer (W. Liu et al., 2003).

Compatibilizers could improve affinity and adhesion between starch and LDPE. These compounds are used in small quantities and treat surfaces of starch and polyethylene polymer; in another word, the interfacial tension of immiscible polymers is reduced by means of compatibilizers and thus morphology of blends would be finer and the degree of continuity increased (J. Davis, 1998; Mortazavi, Ghasemi, \& Oromiehie, 2014). These compounds have chemical groups like carboxyl, anhydride, epoxy, urethane, or oxazoline, which react with functional groups of polymer and starch. The formed covalent and hydrogen bonds improve interfacial adhesion (Chen et al., 2016; Tran et al., 2011).

It has been shown that mechanical properties (such as TS, EB and impact behavior) of LDPE/starch blends improved significantly after addition of different compatibilizers (Chen et al., 2016; Mortazavi et al., 2014; Oromiehie \& Rabiee, 2013).

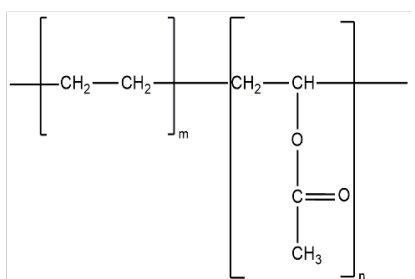

Ethylene-vinyl acetate (EVA)

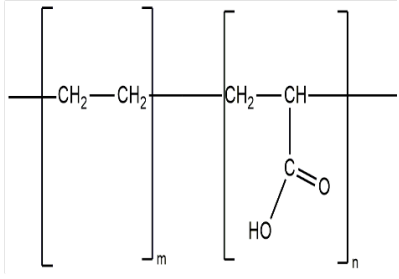

Ethylene-co-acrylic acid (EAA)

Figure 3. Schematic structure of some compatibilizers

Various compatibilizers such as ethylene-vinyl acetate copolymer(EVA) (Prinos et al., 1998), poly(ethylene-co-acrylic acid) (EAA) (Bikiaris et al., 1997), poly(ethylene-grafted-maleic anhydride) (PE-g-MA) copolymers, poly(ethylene-co-glycidyl methacrylate) (PEGMA), poly(ethylene-co-vinyl 
alcohol) (EVOH) and poly(LDPE-g-dibutyl maleate) copolymer have been reported in different studies (Taguet, Huneault, \& Favis, 2009). Schematic structure of some of these compatibilizers is shown in Figure.3.

According to the literature, the most commonly used compatibilizer is PE-g-MA (polyethylenegrafted-maleic anhydride) (Radfar et al., 2020). The anhydride maleic groups of PE-g-MA interact with $-\mathrm{OH}$ groups of starches and on the other hand its PE part reacts with polyethylene matrix
(Ramkumar, Bhattacharya, \& Vaidya, 1997; S. Wang, Yu, \& Yu, 2005).

One of the most important reasons for the popularity of PE-g-MA is the ease of grafting anhydride groups onto other polymers at regular temperatures during the melting process without any significant undesirable side reactions (Kalambur \& Rizvi, 2006). The proposed mechanism of the reaction of starch and PE-g-MA is presented in Figure.4.
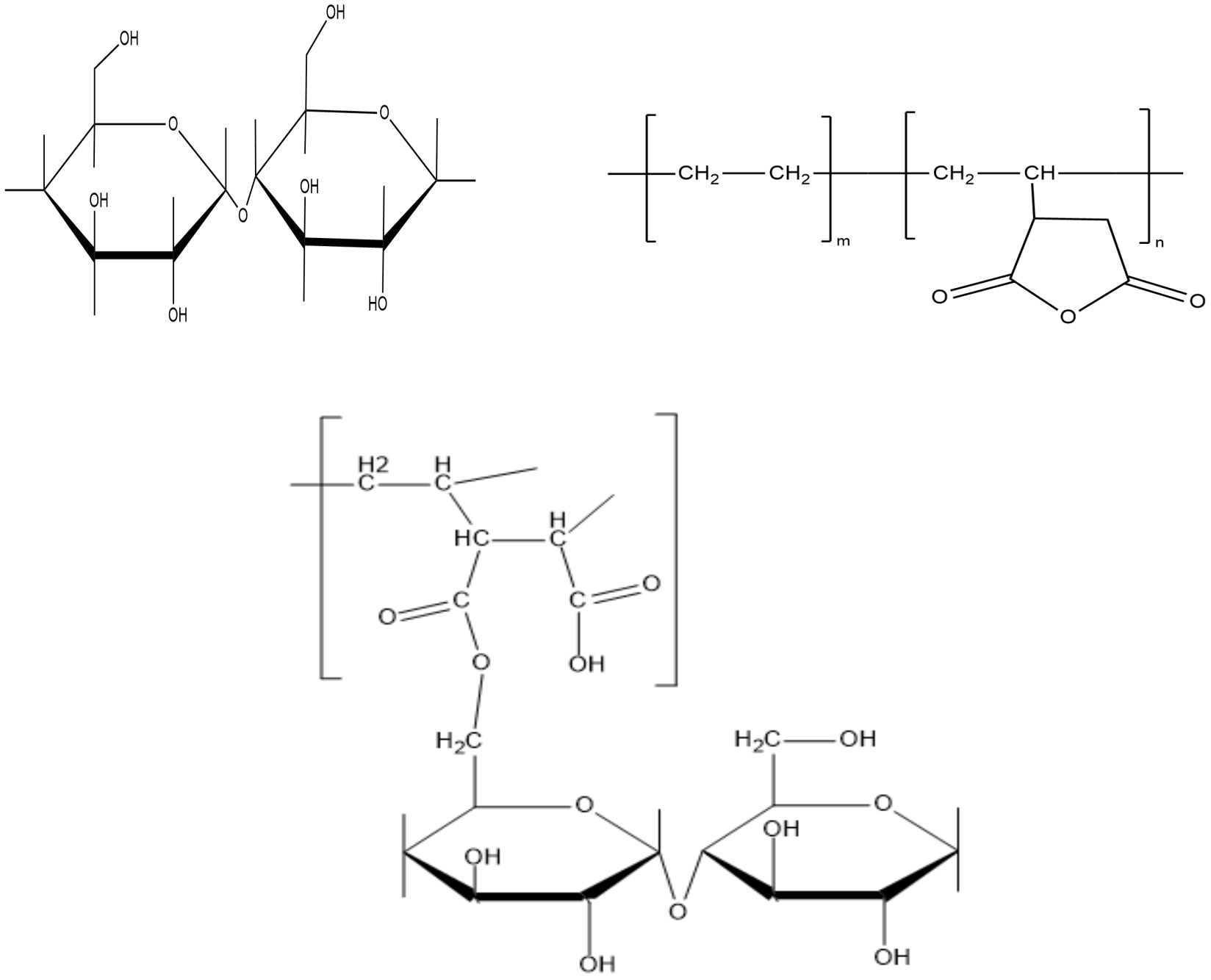

Figure 4. Proposed mechanism for the reaction of maleated PE with starch

Different studies have shown that 3-5 wt\% addition of PE-g-MA improved the mechanical properties of low-density polyethylene and starch blends (Oromiehie \& Rabiee, 2013; Sabetzadeh, Bagheri, \& Masoomi, 2017; Y. J. Wang et al., 2004). It has been proven that compatibilized blends with PE-g-MA had a high elastic network in their structures compared with uncompatibilized ones (Mortazavi et al., 2014).

Ghafoori, Mohammadi, and Ghaffarian (2007) studied the effect of three compatibilizers including poly(ethylene-co-vinyl acetate) (EVA), 
polyethylene grafted with maleic anhydride (PE-g$\mathrm{MA}$ ) and styrene-ethylene-butadiene-styrene grafted with maleic anhydride (SEBS-g-MAH) on the properties of LDPE/starch blends. Their results showed that, by the addition of $3.3 \mathrm{wt} \%$ of these compounds, the adhesion energy of the blends improved. PE-g-MA in comparison with other compatibilizers showed the best results.

Bikiaris et al. (1998) observed that compatibilized LDPE/starch blends prepared with a poly(ethylene-grafted-maleic anhydride) copolymer in comparison with uncompatibilized ones had better mechanical properties.

C.-Y. Huang, Roan, Kuo, and $\mathrm{Lu}$ (2005), prepared high starch/LDPE blends using two compatibilizers (maleic anhydride grafted plasmatreated LDPE and acrylic acid grafted plasmatreated LDPE) after plasma treatment. Their results revealed that MA-g-PLDPE had the best compatibilization effect.

W. Liu et al. (2003) proved that addition of PEg-MA, especially at higher starch contents (20 and $25 \%$ ), could improve interfacial properties of corn starch-LDPE-PE-g-MA blends in comparison with those without compatibilizer. They also showed that the critical interfacial concentration for the addition of PE-g-MA was around $10 \%$ of starch weight in the LDPE/starch blend. At this concentration, compatibilizer saturated the interface between two components (starch and LDPE) and the interfacial tension was reduced at the maximum content. In another research, Raquez et al. (2011) also used the same PE-g-MA concentration $(10$ wt $\%)$ as compatibilizer to improve the interfacial properties of pea starch/LDPE film. They also found that the use of cross-linked pea starch in LDPE film formulation improved the mechanical strength of the film. Scanning electron microscope (SEM) analysis confirmed the improvement of interfacial adhesion between both layers after addition of MA-g-PE. The effect of MA-g-PE on mechanical properties of plasticized tapioca starch blends with the LDPE was examined by Girija and Sailaja (2006). As expected, the authors observed that MA-g-PE could improve mechanical performance of the film. The same results have been reported by other researchers who evaluated the influence of MA-gPE on the mechanical properties of LDPE/starch based films (Sailaja, 2005; S. Wang, Yu, \& Yu, 2004).

\section{Effect of nanoparticles}

Typically, a composite is made from a continuous phase (like polymer) and two or more dispersed phases or fillers (Meeks, Smith, Clark, \& Pantoya, 2017; Nielsen, 1977). If one of the dispersed phases or fillers has at least one dimension less than 100 nanometers, the composite is called nanocomposite (Schadler, Brinson, \& Sawyer, 2007). Incorporation of nanoparticles is considered as an effective technology for improving mechanical and barriers properties of the films. The mechanical and physical properties of nanocomposites usually are different from their constituents. It has been shown that nanocomposites have better mechanical strength and barrier properties in comparison with conventional polymers (Rhim, Park, \& Ha, 2013). Higher aspect ratio and greater surface areas are distinctive features of nanoparticles (De Azeredo, 2009).

Organic or inorganic nanoparticles that are used in food packaging include nanoclay particles or layered silicates (e.g. montmorillonite), metal nanoparticles (e.g. silver), metal oxide nanoparticles (e.g. $\mathrm{Tio}_{2}$ ) and natural biopolymers (e.g. cellulose and chitosan) (Othman, 2014). Among mentioned nano-fillers, the most commonly used materials are clay minerals. This is because they are natural, cheap, available, nontoxic, and relatively processable with significant reinforcement effect. Nanoclays usually have layered structures (nanoplatelets) with dimensions in nanometric range (de Azeredo, 2013; M. M. Reddy, Vivekanandhan, Misra, Bhatia, \& Mohanty, 2013).

Clay minerals could be classified into three groups including kaolinite group (e.g. kaolinite and halloysite), illite group (e.g. hydrous micas, brammalite and celadonite), smectite group (e.g. montmorillonite, hectorite, laponite, bentonite and saponite) (Ismadji, Soetaredjo, \& Ayucitra, 2015). 
During the preparation of nanocomposites from clays, polymeric chains diffuse between silicate layers and form three main arrangements including phase-separated or conventional composite (microcomposite), intercalated and exfoliated ( $\mathrm{J}$. Liu, Boo, Clearfield, \& Sue, 2006). The detailed morphology of each structure is given in Figure 5.

Most of the natural nanoclays are hydrophilic, thus it is difficult to mix them homogeneously with hydrophobic polymers. For this reason, nanoclays are modified by cation exchange reactions (Kampeerapappun, Aht-ong, Pentrakoon, \& Srikulkit, 2007; Ludueña, Vázquez, \& Alvarez, 2013). A lot of suppliers commercially provide different kinds of modified and also intact clays (Table 1). Most of the above-mentioned nanoparticles are modified with quaternary ammonium salts (Ahmed \& ElShishtawy, 2010). Incorporation of nanoparticles, such as clay minerals, especially montmorillonite (MMT), can improve the mechanical properties of polymer blends (Bagdi, Müller, \& Pukánszky, 2006).

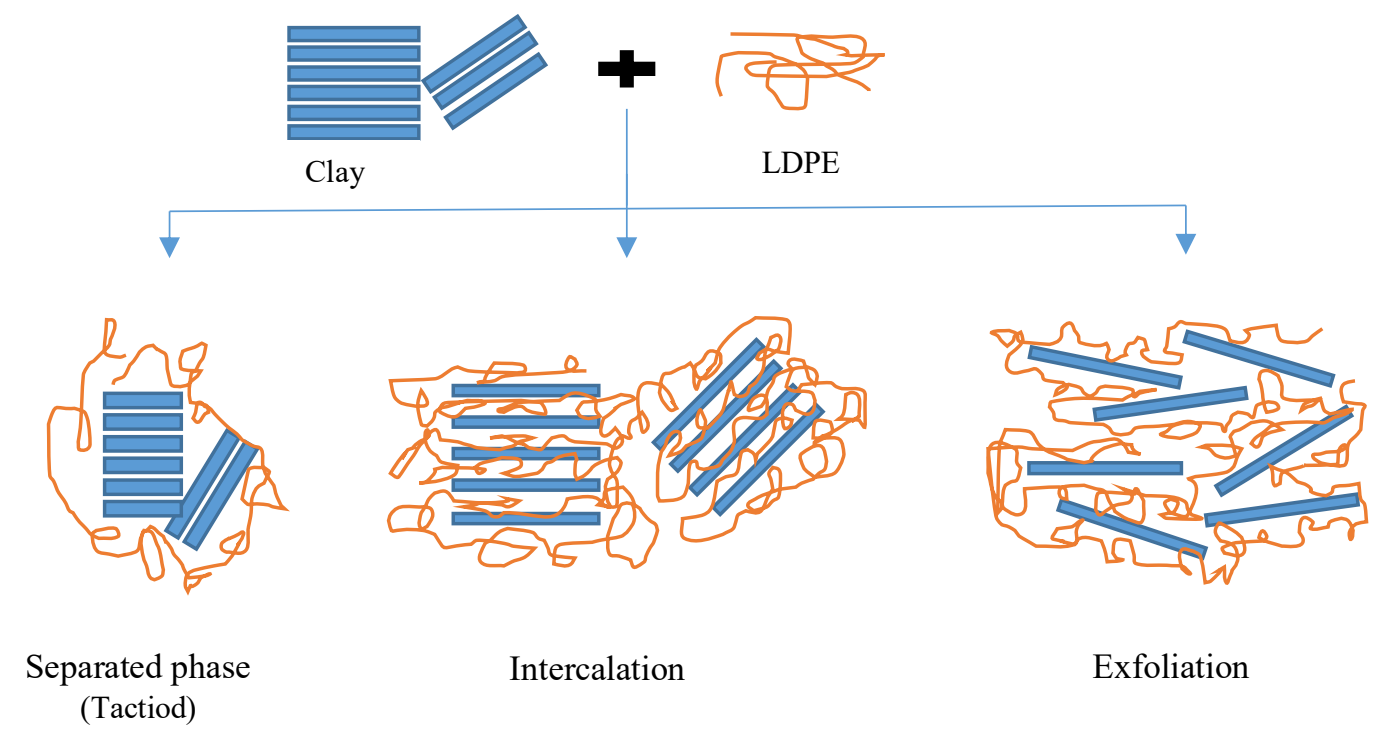

Figure 5. Morphology of three main types of polymer/clay nanocomposite

Table 1-some of most famous commercial clays[97-99]

\begin{tabular}{|c|c|c|c|}
\hline Country & Name of company & Series name & Examples \\
\hline USA & $\begin{array}{c}\text { Southern clay products (now is a part } \\
\text { of BYK Additives Ltd) }\end{array}$ & Cloisite $^{\circledR}$ & Cloisite $^{\circledR} \mathrm{Na}^{+}, 10 \mathrm{~A}, 20 \mathrm{~A}$ and 30B \\
\hline USA & Nanocor, Inc & Nanomer $^{\mathbb{R}}$ & Nanomer $^{\mathbb{R}} 1.30 \mathrm{P} \& 1.44 \mathrm{P}$ \\
\hline Italy & Laviosa Chimica Mineraria & Dellite $^{\circledR}$ & Dellite $^{\circledR}$ 43B \& Dellite ${ }^{\circledR} 72 \mathrm{~T}$ \\
\hline Germany & Süd-Chemie & Nanofil $^{\circledR}$ & Nanofil ${ }^{\circledR} 15$ \& Nanofil ${ }^{\circledR}$ SE3000 \\
\hline
\end{tabular}

Montmorillonite, sepiolite, halloysite, feldspar, bentonite, and nano-cellulose were the most common nanoparticles that have been used in various studies to date as reinforcing agents for producing LDPE/starch films (Musa, Bashir, Ahmad, \& Buntat, 2015). The summary of reported 
results about LDPE/starch nanocomposites is shown in Table 2.

Table 2 - Summary of reported studies using nanoparticles in the LDPE/ starch blends

\begin{tabular}{|c|c|c|c|c|}
\hline Filler type & Method of preparation & $\%$ Loading & $\begin{array}{c}\text { The best } \\
\text { concentration }(\%)\end{array}$ & References \\
\hline Cloisite $^{\circledR} 15 \mathrm{~A}$ & $\begin{array}{l}\text { Montmorillonite is modified with } \\
\text { quaternary ammonium salts }\end{array}$ & $1-5$ & 5 & {$[20]$} \\
\hline Halloysite Nanotubes & $\begin{array}{c}\text { Halloysite nanotubes were } \\
\text { hybridized with kenaf core fibers }\end{array}$ & $0-15$ & 12 & {$[101]$} \\
\hline Bentonite & \multirow{2}{*}{$\begin{array}{l}\text { Nanoparticles used without any } \\
\text { modification }\end{array}$} & $3-15$ & 12 & \multirow{2}{*}[102]{} \\
\hline Feldespar & & $3-15$ & - & \\
\hline Montmorillonite & $\begin{array}{c}\text { MMT modified with sorbitol via } \\
\text { solid state method }\end{array}$ & $2-6$ & 2 & {$[103]$} \\
\hline Sepiolite & Prepared with hydrophobic silane & $2-6$ & 6 & {$[2]$} \\
\hline $\begin{array}{l}\text { Extracted cellulose } \\
\text { nanofibers }\end{array}$ & $\begin{array}{c}\text { Isolated CNFs from wheat straws } \\
\text { directly used without any } \\
\text { modification }\end{array}$ & $6-14$ & 6 & [104] \\
\hline Nanosilics & $\begin{array}{c}\text { Synthesized from rice husk ash } \\
\text { through acid leaching }\end{array}$ & $0.5-2$ & 1.5 & {$[105]$} \\
\hline
\end{tabular}

Chuayjuljit, Wiriyasoonthorn, Jiratumnukul, and Limpanart (2009) studied the mechanical properties of cassava starch, montmorillonite (MMT) and low-density polyethylene (LDPE) nanocomposites. They modified MMT with sorbitol through a solid-state method. Their results indicated that the addition of 2 phr (part per hundred) of MMT and $10 \mathrm{phr}$ of starch to polymer blends resulted in higher mechanical properties of the blends, but these effects decreased with increasing MMT concentration, due to aggregation of MMT in the blends and weak adhesion with polyethylene. Inceoglu and Menceloglu (2013) prepared starch/LDPE films containing compatibilizer, plasticizer, and a Namontmorillonite as a reinforcement filler $(7.5 \mathrm{wt}$ $\%$ ). Solution intercalation method was used for making nanocomposites. Their results showed that produced films in comparison with clay-free composites had superior physical and mechanical properties. Increasing the reinforcement effect of clay nanoparticles due to uniform distribution of clay in plasticized starch-LDPE matrix, as well as prevention of plasticizer evaporation, because of barrier properties of clays, were suggested possible mechanisms for these observations.

In another study, Sabetzadeh, Bagheri, and Masoomi (2014) investigated the effect of organomodified montmorillonite (Cloisite15A) contents on mechanical properties of LDPE/corn starch blends. They prepared LDPE-corn starch mixtures, using a twin-screw extruder, with different nanoclay contents $(0.5,1,2$ and 3 phr). In samples containing $1 \mathrm{phr}$ of nanoclay, ultimate tensile strength and Young's modulus increased compared with samples without nanoclay. The main mentioned reason was the good interaction of nanoparticles with maleic anhydride-grafted lowdensity polyethylene (LDPE-g-MA) segments, in the form of physically cross-linked networks. They also indicated that the possibility of phase separation and also agglomeration of nanoparticles increased in the presence of higher nanoclay contents.

In a complementary study by the same authors, the effect of nanoclay content on properties of ternary LDPE/LLDPE/TPS blends were studied in the presence of PE-g-MA (3 wt.\%) and Cloisite ${ }^{\circledR} 15 \mathrm{~A}$ (1, 3 and 5 phr). The prepared films had intercalated and to some extent exfoliated structures. This study also showed that, along with increasing of nanoclay content from 1 to $5 \mathrm{phr}$, the tensile strength and impact strength of the prepared films increased. The observed results were due to the finer dispersion of nanoparticles and partially formed exfoliated platelets in the matrix. Whereas, elongation at break of the films slightly decreased with the increasing nanoparticle contents of the blends. This behavior was related to stiffing effect of nanoclays in the matrix and thus limited mobility of polymeric chains (Sabetzadeh et al., 2016). 
Bio-nanofibers, like cellulose-based nanofibers, recently have gained a lot of interest because of their renewability, low density, high firmness and strength features (Gray, Hamzeh, Kaboorani, \& Abdulkhani, 2018; A. P. Kumar \& Singh, 2008). Alidadi - Shamsabadi, Behzad, Bagheri, and Nari - Nasrabadi (2015) studied the effects of wheat cellulose nanofibers (6-14 wt \%) on rheological and mechanical behaviors of LDPE/starch nanocomposites. The extracted nanofibers first were blended with starch by using an internal mixer and then the obtained blend was mixed with low-density polyethylene in a single screw extruder. Tensile strength and elongation at break of composites were decreased after addition of nanofibers. This decrease was more marked for elongation at break compared with blank samples. This was mainly due to the incompatibility of cellulose nanofibers and polyethylene mixture. As almost all of the waxy parts of nanofibers were removed during the extraction process, the resultant nanofibers had hydrophilic nature.

\section{Effect of recycled polyethylene}

It is possible to blend starch with recycled LDPE, instead of virgin polyethylene. There is little research in this area. Pedroso and Rosa (2005b) studied the properties of virgin and recycled polyethylene blends with corn starch. Their results showed that the Young's modulus and elongation at break of blends containing recycled polyethylene were significantly higher than those having virgin polyethylene. This was probably due to the higher interaction between recycled polymer and starch. During reprocessing and preparation of recycled polyethylene, because of radical chain reactions, carboxylic and ketone groups are formed, and subsequently, crosslinks and branches along the polymer chains take place. The samples containing recycled polyethylene also had a lower tensile strength than virgin ones.

Similar results were observed by Pedroso and Rosa (2005), who also used reprocessed LDPE (Pedroso \& Rosa, 2005a).

\section{Effect of processing technique}

Various techniques have been used for the preparation of starch/LDPE blends and production of the films (Rodriguez-Gonzalez et al., 2003; Rodriguez - Gonzalez, Virgilio, Ramsay, \& Favis, 2003). St-Pierre, Favis, Ramsay, Ramsay, and Verhoogt (1997) proved that it is possible to control the morphology of the dispersed starch (especially size and shape) in the blends by processing technique. Matzinos et al. (2001) prepared LDPE/starch blends by melt compounding in a twin screw extruder and then processed the obtained LDPE/TPS pellets to films, by injection molding and film blowing techniques. Their findings revealed that films produced by injection molding method had higher tensile strength and Young's modulus compared with blown films. Finer dispersion of starch particles in the matrix and formation of the continuous phase in injected molded films due to the smaller size of thermoplastic starch was the proposed reason for the described observation. They concluded that with injection molding technique it is possible to produce films with up to $40 \% \mathrm{wt}$. of starch.

In another study, B. Raj, K, and Siddaramaiah (2004) investigated the effect of two different processing methods for production of films. In the first method they employed a solution casting technique followed by thermo-pressing, and in the second method they used extrusion process by means of a twin screw extruder for preparation of blends and finally they converted them to films by blowing. Their finding showed that extruded films had better mechanical properties compared to solution casted films due to better molecular alignment.

\section{Conclusions}

The blending of starch with LDPE as a synthetic polymer could increase the biodegradability of obtained films. However, due to the different polarity and weak interaction of the two phases, mechanical properties of the produced films are not satisfactory.

This review shows that LDPE/starch blend mechanical properties are influenced by various factors, such as starch granule characteristics 
(amylose to amylopectin ratio, size and shape), the quantity of starch in the formulation, nature of polyethylene, type of plasticizers.

To improve the mechanical properties of these blends, many approaches have been proposed by researchers. These approaches are mainly based on the reduction of hydrophobicity of starch molecules by processes such as thermoplasticization, crosslinking and esterification and/or surface modification of polymer by the use of a compatibilizer. Beside the above-mentioned factors, utilization of nanoparticles was shown to be an effective strategy for the improvement of film properties. The most important point is that, in many cases, the best results can be achieved by application of a combination of approaches, e.g. thermo-plasticization, compatibilization and addition of nanoparticles.

\section{References}

Ahmed, N. S., \& El-Shishtawy, R. M. (2010). The use of new technologies in coloration of textile fibers. Journal of materials science, 45(5), 1143-1153.

Alidadi-Shamsabadi, M., Behzad, T., Bagheri, R., $\&$ Nari-Nasrabadi, B. (2015). Preparation and characterization of low-density polyethylene/thermoplastic starch composites reinforced by cellulose nanofibers. Polymer Composites, 36(12), 2309-2316.

Aminabhavi, T., Balundgi, R., \& Cassidy, P. (1990). A review on biodegradable plastics. Polymer-Plastics Technology and Engineering, 29(3), 235-262.

Arvanitoyannis, I., Biliaderis, C. G., Ogawa, H., \& Kawasaki, N. (1998). Biodegradable films made from low-density polyethylene (LDPE), rice starch and potato starch for food packaging applications: Part 1. Carbohydrate Polymers, 36(2), 89-104.

Bagdi, K., Müller, P., \& Pukánszky, B. (2006). Thermoplastic starch/layered silicate composites: structure, interaction, properties. Composite Interfaces, 13(1), 1-17.

Bastioli, C. (1998). Properties and applications of Mater-Bi starch-based materials. Polymer degradation and stability, 59(1-3), 263-272.
BeMiller, J. N., \& Whistler, R. L. (2009). Starch: chemistry and technology: Academic Press.

Bikiaris, D., Prinos, J., Koutsopoulos, K., Vouroutzis, N., Pavlidou, E., Frangis, N., \& Panayiotou, C. (1998). LDPE/plasticized starch blends containing PE-g-MA copolymer as compatibilizer. Polymer degradation and stability, 59(1-3), 287-291.

Bikiaris, D., Prinos, J., \& Panayiotou, C. (1997). Effect of EAA and starch on the thermooxidative degradation of LDPE. Polymer degradation and stability, 56(1), 1-9.

Cerclé, C., Sarazin, P., \& Favis, B. D. (2013). High performance polyethylene/thermoplastic starch blends through controlled emulsification phenomena. Carbohydrate Polymers, 92(1), 138-148.

Chen, X., Zhou, L., Pan, X., Hu, J., Hu, Y., \& Wei, S. (2016). Effect of different compatibilizers on the mechanical and thermal properties of starch/polypropylene blends. Journal of applied polymer science, 133(17).

Chiu, F.-C., Lai, S.-M., \& Ti, K.-T. (2009). Characterization and comparison of metallocene-catalyzed

polyethylene/thermoplastic starch blends and nanocomposites. Polymer Testing, 28(3), 243250.

Chuayjuljit, S., Wiriyasoonthorn, S., Jiratumnukul, N., \& Limpanart, S. (2009). Preparation of Natural Rubber/Cassava Starch/Organomontmorillonite Biodegradable Nanocomposite Elastomers. Polymers \& Polymer Composites, 17(3), 173.

Da Róz, A., Carvalho, A., Gandini, A., \& Curvelo, A. (2006). The effect of plasticizers on thermoplastic starch compositions obtained by melt processing. Carbohydrate polymers, 63(3), 417-424.

Datta, D., \& Halder, G. (2019). Effect of Rice Husk Derived Nanosilica on the Structure, Properties and Biodegradability of Corn-Starch/LDPE Composites. Journal of Polymers and the Environment, 27(4), 710-727. doi: 10.1007/s10924-019-01386-2 
Davis, G. (2003). Characterization and characteristics of degradable polymer sacks. Materials Characterization, 51(2), 147-157.

Davis, J. (1998). Flame retardants: halogen-free systems (including phosphorus additives). Plastics Additives: An AZ Reference, 278-286.

De Azeredo, H. M. (2009). Nanocomposites for food packaging applications. Food research international, 42(9), 1240-1253.

de Azeredo, H. M. (2013). Antimicrobial nanostructures in food packaging. Trends in Food Science \& Technology, 30(1), 56-69.

De Paiva, L. B., Morales, A. R., \& Díaz, F. R. V. (2008). Organoclays: properties, preparation and applications. Applied clay science, 42(1), $8-24$.

Eskandarinia, A., Rafienia, M., Navid, S., \& Agheb, M. (2018). Physicochemical, Antimicrobial and Cytotoxic Characteristics of Corn Starch Film Containing Propolis for Wound Dressing. Journal of Polymers and the Environment, 26(8), 3345-3351.

Evangelista, R. L., Sung, W., Jane, J. L., Gelina, R. J., \& Nikolov, Z. L. (1991). Effect of compounding and starch modification on properties of starch-filled low-density polyethylene. Industrial \& engineering chemistry research, 30(8), 1841-1846.

Fang, J., Fowler, P., Tomkinson, J., \& Hill, C. (2002). The preparation and characterisation of a series of chemically modified potato starches. Carbohydrate Polymers, 47(3), 245-252.

Fishman, M., Coffin, D., Konstance, R., \& Onwulata, C. (2000). Extrusion of pectin/starch blends plasticized with glycerol. Carbohydrate Polymers, 41(4), 317-325.

Gage, P. (1990). Degradable polyethylene film-the facts. Tappi journal, 73(10), 161-169.

Garg, S., \& Jana, A. K. (2007). Studies on the properties and characteristics of starch-LDPE blend films using cross-linked, glycerol modified, cross-linked and glycerol modified starch. European polymer journal, 43(9), 39763987.

Ghafoori, M., Mohammadi, N., \& Ghaffarian, S. (2007). The role of joint viscoelastic function in the adhesion of low-density polyethylene to thermoplastic starch. Journal of Adhesion Science and Technology, 21(11), 1059-1069.

Ghanbarzadeh, B., Almasi, H., \& Entezami, A. A. (2011). Improving the barrier and mechanical properties of corn starch-based edible films: Effect of citric acid and carboxymethyl cellulose. Industrial Crops and Products, 33(1), 229-235.

Girija, B., \& Sailaja, R. (2006). Low-density polyethylene/plasticized tapioca starch blends with the low-density polyethylene functionalized with maleate ester: Mechanical and thermal properties. Journal of Applied Polymer Science, 101(2), 1109-1120.

Gomez, M., \& Aguilera, J. (1984). A physicochemical model for extrusion of corn starch. Journal of Food Science, 49(1), 40-43.

Gray, N., Hamzeh, Y., Kaboorani, A., \& Abdulkhani, A. (2018). Influence of cellulose nanocrystal on strength and properties of low density polyethylene and thermoplastic starch composites. Industrial Crops and Products, 115, 298-305. doi: https://doi.org/10.1016/j.indcrop.2018.02.017

Griffin, G. (1994). Starch polymer blends. Polymer degradation and stability, 45(2), 241-247.

Griffin, G. J. L. (1977). Biodegradable synthetic resin sheet material containing starch and a fatty material: Google Patents.

Hamerstrand, G., Hofreiter, B., \& Mehltretter, C. (1960). Determination of the extent of reaction between epichlorohydrin and starch. Cereal Chem, 37(4), 519-524.

Huang, C.-Y., Roan, M.-L., Kuo, M.-C., \& Lu, W.L. (2005). Effect of compatibiliser on the biodegradation and mechanical properties of high-content starch/low-density polyethylene blends. Polymer degradation and stability, 90(1), 95-105.

Huang, J. C., Shetty, A. S., \& Wang, M. S. (1990). Biodegradable plastics: a review. Advances in Polymer Technology, 10(1), 23-30.

Huang, M., Yu, J., \& Ma, X. (2005). Ethanolamine as a novel plasticiser for thermoplastic starch. Polymer degradation and stability, 90(3), 501507. 
Inceoglu, F., \& Menceloglu, Y. Z. (2013). Transparent low-density polyethylene/starch nanocomposite films. Journal of applied polymer science, 129(4), 1907-1914.

Ismadji, S., Soetaredjo, F. E., \& Ayucitra, A. (2015). Natural clay minerals as environmental cleaning agents Clay Materials for Environmental Remediation (pp. 5-37): Springer

Jawaid, M., \& el Kacem, A. (2016). Nanoclay Reinforced Polymer Composites: Nanocomposites and Bionanocomposites: Springer.

Kahar, A., Ismail, H., \& Othman, N. (2012). Morphology and tensile properties of highdensity polyethylene/natural rubber/thermoplastic tapioca starch blends: The effect of citric acid-modified tapioca starch. Journal of applied polymer science, 125(1), 768-775.

Kalambur, S., \& Rizvi, S. S. (2006). An overview of starch-based plastic blends from reactive extrusion. Journal of Plastic Film \& Sheeting, 22(1), 39-58.

Kalichevsky, M. T., \& Blanshard, J. M. (1993). The effect of fructose and water on the glass transition of amylopectin. Carbohydrate Polymers, 20(2), 107-113.

Kampeerapappun, P., Aht-ong, D., Pentrakoon, D., \& Srikulkit, K. (2007). Preparation of cassava starch/montmorillonite composite film. Carbohydrate Polymers, 67(2), 155-163.

Kiatkamjornwong, S., Thakeow, P., \& Sonsuk, M. (2001). Chemical modification of cassava starch for degradable polyethylene sheets. Polymer degradation and stability, 73(2), 363375.

Kim, M., \& Lee, S.-J. (2002). Characteristics of crosslinked potato starch and starch-filled linear low-density polyethylene films. Carbohydrate Polymers, 50(4), 331-337.

Kokini, J., Lih-Shiuh, L., \& Chedid, L. L. (1992). Effect of starch on starch theological properties. Food technology, 46(6), 124-139.
Kumar, A. P., \& Singh, R. P. (2008). Biocomposites of cellulose reinforced starch: Improvement of properties by photo-induced crosslinking. Bioresource Technology, 99(18), 8803-8809.

Kumar, K. A., \& Soundararajan, S. (2016). Studies on the Mechanical Properties and UVAccelerated Weathering of LDPE with Benzophenone and Carboxy Methylated Starch. Polymers from Renewable Resources, 7(4), 155.

Kuniak, L., \& Marchessault, R. (1972). Study of the crosslinking reaction between epichlorohydrin and starch. Starch-Stärke, 24(4), 110-116.

Lim, S., Jane, J. L., Rajagopalan, S., \& Seib, P. A. (1992). Effect of starch granule size on physical properties of starch-filled polyethylene film. Biotechnology progress, 8(1), 51-57.

Liu, H., Xie, F., Yu, L., Chen, L., \& Li, L. (2009). Thermal processing of starch-based polymers. Progress in Polymer Science, 34(12), 13481368.

Liu, J., Boo, W.-J., Clearfield, A., \& Sue, H.-J. (2006). Intercalation and exfoliation: a review on morphology of polymer nanocomposites reinforced by inorganic layer structures. Materials and Manufacturing Processes, 21(2), 143-151.

Liu, W., Wang, Y. J., \& Sun, Z. (2003). Effects of polyethylene-grafted maleic anhydride (PE-gMA) on thermal properties, morphology, and tensile properties of low-density polyethylene (LDPE) and corn starch blends. Journal of applied polymer science, 88(13), 2904-2911.

Lorcks, J., Pommeranz, W., Klenke, K., Schmidt, H., \& Heuer, J. (2000). Process for producing thermoplastic starch: Google Patents.

Lu, D., Xiao, C., \& Xu, S. (2009). Starch-based completely biodegradable polymer materials. Express polymer letters, 3(6), 366-375.

Ludueña, L. N., Vázquez, A., \& Alvarez, V. A. (2013). Effect of the type of clay organomodifier on the morphology, thermal/mechanical/impact/barrier properties and biodegradation in soil of polycaprolactone/clay nanocomposites. 
Journal of applied polymer science, 128(5), 2648-2657.

Mali, S., \& Grossmann, M. V. E. (2003). Effects of yam starch films on storability and quality of fresh strawberries (Fragaria ananassa). Journal of agricultural and food chemistry, 51(24), 7005-7011.

Mani, R., \& Bhattacharya, M. (1998). Properties of injection moulded starch/synthetic polymer blends-III. Effect of amylopectin to amylose ratio in starch. European polymer journal, 34(10), 1467-1475.

Matzinos, P., Bikiaris, D., Kokkou, S., \& Panayiotou, C. (2001). Processing and characterization of LDPE/starch products. Journal of applied polymer science, 79(14), 2548-2557.

Matzinos, P., Tserki, V., Gianikouris, C., Pavlidou, E., \& Panayiotou, C. (2002). Processing and characterization of LDPE/starch/PCL blends. European Polymer Journal, 38(9), 1713-1720.

Mazerolles, T., Heuzey, M. C., Soliman, M., Martens, H., Kleppinger, R., \& Huneault, M. A. (2019). Development of co-continuous morphology in blends of thermoplastic starch and low-density polyethylene. Carbohydrate Polymers, 206, 757-766. doi: https://doi.org/10.1016/j.carbpol.2018.11.038

Meeks, K., Smith, D. K., Clark, B., \& Pantoya, M. L. (2017). Percolation of a metallic binder in energy generating composites. Journal of Materials Chemistry A, 5(15), 7200-7209. doi: 10.1039/C7TA00689F

Mohammadi Nafchi, A., Moradpour, M., Saeidi, M., \& Alias, A. K. (2013). Thermoplastic starches: Properties, challenges, and prospects. Starch-Stärke, 65(1-2), 61-72.

Mortazavi, S., Ghasemi, I., \& Oromiehie, A. (2014). Morphological and rheological properties of (low-density polyethylene)/thermoplastic starch blend: investigation of the role of high elastic network. Journal of Vinyl and Additive Technology, 20(4), 250-259.

Musa, F. N., Bashir, N., Ahmad, M. H., \& Buntat, Z. (2015). Electrical treeing in high voltage insulations: a review on nanocomposite insulating materials and their processing techniques. JOURNAL OF OPTOELECTRONICS AND ADVANCED MATERIALS, 17(3-4), 462-476.

Nakamura, E., Cordi, L., Almeida, G., Duran, N., $\&$ Mei, L. I. (2005). Study and development of LDPE/starch partially biodegradable compounds. Journal of Materials Processing Technology, 162, 236-241.

Nawang, R., Danjaji, I., Ishiaku, U., Ismail, H., \& Ishak, Z. M. (2001). Mechanical properties of sago starch-filled linear low density polyethylene (LLDPE) composites. Polymer Testing, 20(2), 167-172.

Nazir, M. S., Kassim, M. H. M., Mohapatra, L., Gilani, M. A., Raza, M. R., \& Majeed, K. (2016). Characteristic Properties of Nanoclays and Characterization of Nanoparticulates and Nanocomposites Nanoclay Reinforced Polymer Composites (pp. 35-55): Springer

Nielsen, L. E. (1977). Polymeric composite systems with two continuous phases. Journal of applied polymer science, 21(6), 1579-1584.

Nikazar, M., Safari, B., Bonakdarpour, B., \& Milani, Z. (2005). Improving the biodegradability and mechanical strength of corn starch-LDPE blends through formulation modification. Iranian Polymer Journal, 14(12), 1050.

Ning, W., Jiugao, Y., Xiaofei, M., \& Ying, W. (2007). The influence of citric acid on the properties of thermoplastic starch/linear lowdensity polyethylene blends. Carbohydrate Polymers, 67(3), 446-453.

Obasi, H., \& Igwe, I. (2014). Effects of native cassava starch and compatibilizer on biodegradable and tensile properties of polypropylene. American J. Eng. Res, 3(2), 96104.

Olsson, E., Menzel, C., Johansson, C., Andersson, R., Koch, K., \& Järnström, L. (2013). The effect of $\mathrm{pH}$ on hydrolysis, cross-linking and barrier properties of starch barriers containing citric acid. Carbohydrate Polymers, 98(2), 1505-1513. doi: https://doi.org/10.1016/j.carbpol.2013.07.040 
Orford, P., Parker, R., Ring, S., \& Smith, A. (1989). Effect of water as a diluent on the glass transition behaviour of malto-oligosaccharides, amylose and amylopectin. International Journal of Biological Macromolecules, 11(2), 91-96.

Oromiehie, A., Lari, T. T., \& Rabiee, A. (2013). Physical and thermal mechanical properties of corn starch/LDPE composites. Journal of Applied Polymer Science, 127(2), 1128-1134.

Oromiehie, A., \& Rabiee, A. (2013). Physical and thermal mechanical properties of corn starch/LDPE composites. Journal of applied polymer science, 127(2), 1128-1134.

Othman, S. H. (2014). Bio-nanocomposite materials for food packaging applications: types of biopolymer and nano-sized filler. Agriculture and Agricultural Science Procedia, 2, 296-303.

Pedroso, A. G., \& Rosa, D. S. (2005a). Effects of the compatibilizer PE-g-GMA on the mechanical, thermal and morphological properties of virgin and reprocessed LDPE/corn starch blends. Polymers for advanced technologies, 16(4), 310-317. doi: 10.1002/pat.581

Pedroso, A. G., \& Rosa, D. S. (2005b). Mechanical, thermal and morphological characterization of recycled LDPE/corn starch blends. Carbohydrate Polymers, 59(1), 1-9. doi: https://doi.org/10.1016/j.carbpol.2004.08.018

Perry, P., \& Donald, A. (2002). The effect of sugars on the gelatinisation of starch. Carbohydrate Polymers, 49(2), 155-165.

Phetwarotai, W., Potiyaraj, P., \& Aht-Ong, D. (2012). Characteristics of biodegradable polylactide/gelatinized starch films: Effects of starch, plasticizer, and compatibilizer. Journal of applied polymer science, 126(S1).

Poutanen, K., \& Forssell, P. (1996). Modification of starch properties with plasticizers. Trends in polymer science, 4(4), 128-132.

Prinos, J., Bikiaris, D., Theologidis, S., \& Panayiotou, C. (1998). Preparation and characterization of LDPE/starch blends containing ethylene/vinyl acetate copolymer as compatibilizer. Polymer Engineering \& Science, 38(6), 954-964.

Psomiadou, E., Arvanitoyannis, I., Biliaderis, C. G., Ogawa, H., \& Kawasaki, N. (1997). Biodegradable films made from low density polyethylene (LDPE), wheat starch and soluble starch for food packaging applications. Part 2. Carbohydrate Polymers, 33(4), 227-242.

Pushpadass, H. A., Bhandari, P., \& Hanna, M. A. (2010). Effects of LDPE and glycerol contents and compounding on the microstructure and properties of starch composite films. Carbohydrate Polymers, 82(4), 1082-1089.

Radfar, R., Farhoodi, M., Ghasemi, I., Khaneghah, A. M., Shahraz, F., \& Hosseini, H. (2019). Assessment of phenolic contents and antioxidant and antibacterial activities of extracts from four varieties of Iranian date Palm (Phoenix dactylifera L.) seeds. Applied Food Biotechnology, 6(3), 173-184.

Radfar, R., Hosseini, H., Farhodi, M., Ghasemi, I., Średnicka-Tober, D., Shamloo, E., \& Khaneghah, A. M. (2020). Optimization of antibacterial and mechanical properties of an active LDPE/starch/nanoclay nanocomposite film incorporated with date palm seed extract using D-optimal mixture design approach. International Journal of Biological Macromolecules.

Raghavan, D., \& Emekalam, A. (2001). Characterization of starch/polyethylene and starch/polyethylene/poly (lactic acid) composites. Polymer degradation and stability, 72(3), 509-517.

Raj, B., Annadurai, V., Somashekar, R., Raj, M., \& Siddaramaiah, S. (2001). Structure-property relation in low-density polyethylene-starch immiscible blends. European polymer journal, 37(5), 943-948.

Raj, B., K, U. S., \& Siddaramaiah. (2004). Low density polyethylene/starch blend films for food packaging applications. Advances in Polymer Technology, 23(1), 32-45. doi: 10.1002/adv. 10068

Raj, M., Savaliya, R., Joshi, S., \& Raj, L. (2018). Studies on Blends of Modified Starch-LDPE. 
Polymer Science, Series A, 60(6), 805-815. doi: $10.1134 / \mathrm{s} 0965545 \times 18060081$

Ramkumar, D., Bhattacharya, M., \& Vaidya, U. R. (1997). Properties of injection moulded starch/synthetic polymer blends-II. Evaluation of mechanical properties. European polymer journal, 33(5), 729-742.

Raquez, J. M., Bourgeois, A., Jacobs, H., Degée, P., Alexandre, M., \& Dubois, P. (2011). Oxidative degradations of oxodegradable LDPE enhanced with thermoplastic pea starch: Thermo-mechanical properties, morphology, and UV-ageing studies. Journal of Applied Polymer Science, 122(1), 489-496.

Reddy, M. M., Vivekanandhan, S., Misra, M., Bhatia, S. K., \& Mohanty, A. K. (2013). Biobased plastics and bionanocomposites: Current status and future opportunities. Progress in Polymer Science, 38(10), 16531689.

Reddy, N., \& Yang, Y. (2010). Citric acid crosslinking of starch films. Food Chemistry, 118(3), 702-711.

Rhim, J.-W., Park, H.-M., \& Ha, C.-S. (2013). Bionanocomposites for food packaging applications. Progress in Polymer Science, 38(10), 1629-1652.

Rodriguez-Gonzalez, F., Ramsay, B., \& Favis, B. (2003). High performance LDPE/thermoplastic starch blends: a sustainable alternative to pure polyethylene. Polymer, 44(5), 1517-1526.

Rodriguez-Gonzalez, F., Virgilio, N., Ramsay, B., \& Favis, B. (2003). Influence of melt drawing on the morphology of one-and two-step processed LDPE/thermoplastic starch blends. Advances in Polymer Technology, 22(4), 297305.

Sabetzadeh, M., Bagheri, R., \& Masoomi, M. (2012). Effect of corn starch content in thermoplastic starch/low-density polyethylene blends on their mechanical and flow properties. Journal of applied polymer science, 126(S1).

Sabetzadeh, M., Bagheri, R., \& Masoomi, M. (2014). Effect of organomodified montmorillonite concentration on tensile and flow properties of low-density polyethylenethermoplastic corn starch blends. Journal of
Thermoplastic Composite Materials, 27(8), 1022-1036.

Sabetzadeh, M., Bagheri, R., \& Masoomi, M. (2016). Effect of nanoclay on the properties of low density polyethylene/linear low density polyethylene/thermoplastic starch blend films. Carbohydrate Polymers, 141, 75-81.

Sabetzadeh, M., Bagheri, R., \& Masoomi, M. (2017). Morphology and rheological properties of compatibilized low-density polyethylene/linear polyethylene/thermoplastic starch blends. Journal of applied polymer science, 134(16).

Sagar, A. D., \& Merrill, E. W. (1995). Properties of fatty-acid esters of starch. Journal of applied polymer science, 58(9), 1647-1656.

Sailaja, R. (2005). Mechanical properties of esterified tapioca starch-LDPE blends using LDPE-co-glycidyl methacrylate as compatibilizer. Polymer international, 54(2), 286-296.

Sailaja, R., \& Seetharamu, S. (2009). Mechanical and thermal properties of LDPE-cellulose acetate phthalate blends-Effect of maleic anhydride-grafted LDPE compatibilizer. Journal of applied polymer science, 112(2), 649-659.

Samper-Madrigal, M., Fenollar, O., Dominici, F., Balart, R., \& Kenny, J. (2015). The effect of sepiolite on the compatibilization of polyethylene-thermoplastic starch blends for environmentally friendly films. Journal of materials science, 50(2), 863-872.

Sarifuddin, N., \& Ismail, H. (2013). Comparative Study on the Effect of Bentonite or Feldspar Filled Low-Density

Polyethylene/Thermoplastic Sago Starch/Kenaf Core Fiber Composites (Vol. 8).

Sarifuddin, N., Ismail, H., \& Ahmad, Z. (2012). EFFECT OF FIBER LOADING ON PROPERTIES OF THERMOPLASTIC SAGO STARCH/KENAF CORE FIBER BIOCOMPOSITES (Vol. 7).

Schadler, L., Brinson, L., \& Sawyer, W. (2007). Polymer nanocomposites: a small part of the story. JOM Journal of the Minerals, Metals and Materials Society, 59(3), 53-60. 
Seidenstücker, T., \& Fritz, H. G. (1999). Compounding Procedure, Processing Behaviour and Property Profiles of Polymeric Blends Based on Thermoplastic Poly (esterurethanes) and Destructurized Starch. StarchStärke, 51(2-3), 93-102.

Shi, R., Liu, Q., Ding, T., Han, Y., Zhang, L., Chen, D., \& Tian, W. (2007). Ageing of soft thermoplastic starch with high glycerol content. Journal of applied polymer science, 103(1), 574-586.

Shimao, M. (2001). Biodegradation of plastics. Current opinion in Biotechnology, 12(3), 242247.

Shogren, R. L., Swanson, C. L., \& Thompson, A. R. (1992). Extrudates of cornstarch with urea and glycols: structure/mechanical property relations. Starch-Stärke, 44(9), 335-338.

Smits, A., Wübbenhorst, M., Kruiskamp, P., Van Soest, J., Vliegenthart, J., \& Van Turnhout, J. (2001). Structure evolution in amylopectin/ethylene glycol mixtures by $\mathrm{H}$ bond formation and phase separation studied with dielectric relaxation spectroscopy. The Journal of Physical Chemistry B, 105(24), 5630-5636.

St-Pierre, N., Favis, B., Ramsay, B., Ramsay, J., \& Verhoogt, H. (1997). Processing and characterization of thermoplastic starch/polyethylene blends. Polymer, 38(3), 647-655.

Swanson, C., Westhoff, R., \& Doane, W. (1988). Modified starches in plastic films. Paper presented at the Corn utilisation conference II.

Swift, G. (2000). Polymers, Environmentally Degradable. Kirk-Othmer Encyclopedia of Chemical Technology.

Taghizadeh, A., \& Favis, B. D. (2013). Effect of high molecular weight plasticizers on the gelatinization of starch under static and shear conditions. Carbohydrate Polymers, 92(2), 1799-1808.

doi:

https://doi.org/10.1016/j.carbpol.2012.11.018

Taghizadeh, A., Sarazin, P., \& Favis, B. D. (2013). High molecular weight plasticizers in thermoplastic starch/polyethylene blends. Journal of materials science, 48(4), 1799-1811.
Taguet, A., Huneault, M. A., \& Favis, B. D. (2009). Interface/morphology relationships in polymer blends with thermoplastic starch. Polymer, 50(24), 5733-5743.

Thakore, I., Iyer, S., Desai, A., Lele, A., \& Devi, S. (1999). Morphology, thermomechanical properties, and biodegradability of low density polyethylene/starch blends. Journal of applied polymer science, 74(12), 2791-2802.

Thiebaud, S., Aburto, J., Alric, I., Borredon, E., Bikiaris, D., Prinos, J., \& Panayiotou, C. (1997). Properties of fatty-acid esters of starch and their blends with LDPE. Journal of applied polymer science, 65(4), 705-721.

Torabi Angaji, M., \& Hagheeghatpadjooh, H. R. (2004). Preparation of Biodegradable Low Density Polyethylene by Starch-Urea Composition for Agricultural Applications. IRANIAN JOURNAL OF CHEMISTRY AND CHEMICAL ENGINEERING, 23, 7-12.

Tran, T., Lee, B. H., Yang, H. S., Chotineeranat, S., Sriroth, K., \& Kim, H. J. (2011). Use of starch granules melting to control the properties of bio-flour filled polypropylene and poly (butylene succinate) composites: Physicochemical properties. Starch-Stärke, 63(10), 649-654.

Wang, S., Yu, J., \& Yu, J. (2004). Influence of maleic anhydride on the compatibility of thermal plasticized starch and linear lowdensity polyethylene. Journal of Applied Polymer Science, 93(2), 686-695.

Wang, S., Yu, J., \& Yu, J. (2005). Compatible thermoplastic starch/polyethylene blends by one-step reactive extrusion. Polymer international, 54(2), 279-285.

Wang, Y. J., Liu, W., \& Sun, Z. (2004). Effects of glycerol and PE-g-MA on morphology, thermal and tensile properties of LDPE and rice starch blends. Journal of applied polymer science, 92(1), 344-350.

Wesslén, K. B., \& Wesslen, B. (2002). Synthesis of amphiphilic amylose and starch derivatives. Carbohydrate Polymers, 47(4), 303-311.

Willett, J. (1994). Mechanical properties of LDPE/granular starch composites. Journal of 
applied polymer science, 54(11), 1685-1695.

\section{Acknowledgements}

This study was supported financially by the National Nutrition and Food Technology

Research Institute (NNFTRI) of Iran, and we deeply appreciate the support. 